University of Wollongong

Research Online

Faculty of Engineering - Papers (Archive)

Faculty of Engineering and Information

Sciences

2008

\title{
Validation of a resonant frequency model for polypyrrole trilayer actuators
}

S. W. John

University of Wollongong, swj56@uow.edu.au

G. Alici

University of Wollongong, gursel@uow.edu.au

C. Cook

University of Wollongong, chris_cook@uow.edu.au

Follow this and additional works at: https://ro.uow.edu.au/engpapers

Part of the Engineering Commons

https://ro.uow.edu.au/engpapers/484

\section{Recommended Citation}

John, S. W.; Alici, G.; and Cook, C.: Validation of a resonant frequency model for polypyrrole trilayer actuators 2008.

https://ro.uow.edu.au/engpapers/484

Research Online is the open access institutional repository for the University of Wollongong. For further information contact the UOW Library: research-pubs@uow.edu.au 


\title{
Validation of Resonant Frequency Model for Polypyrrole Trilayer Actuators
}

\author{
Stephen W. John, Gursel Alici, and Christopher D. Cook
}

\begin{abstract}
Conducting polymers are new materials that can be used as low-voltage actuators and active flexure joints, scaling down to the microscale; however, many devices based on these actuators are limited because they can only operate when submerged in an electrolyte. Conducting polymer trilayer actuators are laminated structures with a wide range of potential applications as they are capable of operating both in air and liquid environments, but their dynamic behavior is not yet fully understood. With the view to developing a comprehensive dynamic model of trilayer actuators, this paper presents the experimentally obtained frequency response of the actuator displacement, as measured using a laser displacement sensor. A model of the resonant frequency is also presented and then comprehensively validated using actuators of various geometry and loading. This model can be used to: 1) estimate properties of the trilayer actuator from experimental measurements; 2) quantify and optimize an actuator's dynamic behavior as a function of geometry; and 3) facilitate the use of these actuators as a component in practical applications, such as force and motion control systems.
\end{abstract}

Index Terms-Actuator, conducting polymers, identification, resonance.

\section{INTRODUCTION}

$\mathbf{C}$ ONDUCTING polymers are a new class of material able to inherently conduct electricity, and they have been found to change volume with small changes in applied voltage, allowing their use as actuators [1]. The attraction of conducting polymer actuators are the low actuation voltages required to produce movement, biocompatibility, operation in liquid or air environments, controllable manufacture down to the microscale [2], and the useable stresses and strains that are generated [1]. Bending actuators show potential as active flexure joints for manipulation devices approaching the microscale [3]-[5], with the generated tip forces $(<10 \mathrm{mN}$ [3], [6], [7]) capable of manipulating small objects [4], [6], but their static and dynamic behavior needs to be understood and modeled before these actuators can be fully exploited in practical manipulation systems.

The linear actuation behavior of individual conducting polymer flat films and tubular structures has been studied [8]-[14], including dynamic properties such as strain rates [8], [15] and

Manuscript received January 10, 2008; revised April 10, 2008. Published August 13, 2008 (projected). Recommended by Technical Editor I-M. Chen.

S. W. John is with the School of Mechanical, Materials and Mechatronic Engineering, University of Wollongong, Wollongong, NSW 2522, Australia (e-mail: swj56@uow.edu.au).

G. Alici is with the School of Mechanical, Materials and Mechatronic Engineering and the Australian Research Council (ARC) Center of Excellence on Electromaterials Science, University of Wollongong, Wollongong, NSW 2522, Australia (e-mail: gursel@uow.edu.au).

C. D. Cook is with the Faculty of Engineering, University of Wollongong, Wollongong, NSW 2522, Australia (e-mail: ccook@uow.edu.au).

Color versions of one or more of the figures in this paper are available online at http://ieeexplore.ieee.org.

Digital Object Identifier 10.1109/TMECH.2008.2000883 the modeling of impedance [10], [13]; however, the practical use of these actuator configurations are limited as they change volume only when the device is in contact with free ions, typically in the form of a liquid electrolyte.

Some laminated bending conducting polymer actuators, called trilayers, have a self-contained electrolyte source that allows for a wider range of potential applications, as they can operate in both air and liquid environments. The bending profile and force outputs of trilayers have been examined near or at steady state, with some models proposed [6], [16], [17]. Initial investigations into the dynamic response of trilayers have also been conducted, with Kaneto et al. [18] identifying the displacement of a polyaniline trilayer at $44 \mathrm{~Hz}$, but no other displacement frequencies were probed, and it was not reported whether it was at resonance. Madden et al. [9] examined the displacement at multiple input voltage frequencies, but did not report resonance, while Wu et al. [7] are able to manually identify resonance up to $90 \mathrm{~Hz}$. The phase response of the polypyrrole trilayer benders has not been identified to date, and a dynamic model for trilayer displacement does not yet exist.

The research described in this paper contributes to the understanding of the dynamic behavior of conducting polymer actuators by presenting, for the first time, the frequency response of the conducting polymer trilayer actuator displacement, including phase shift. A resonant frequency model, based on the theory for cantilever beams, is presented for the trilayer structure and comprehensively validated using over 300 actuators of different geometries and loadings. This model can be used to estimate unknown actuator properties, such as mass or elastic modulus, from experimental measurements. The model will also allow the quantification and optimization of the dynamic performance of trilayer actuators and represents a significant step toward the development of a fully dynamic model for these devices.

\section{A. Actuator Structure}

Laminations of active conducting polymers and inactive substrates form one type of actuator, with the volume change (or strain) of the polymer working against the inactive substrate to produce a bending action. Single-polymer layers on a substrate are known as bilayers (or bimorphs) [2], [5], [19], [20] but these have limited practical applications in that, like single films, they can only operate while submerged in liquid, typically an electrolyte. This has been overcome with the trilayer actuator structure [7], where an inactive substrate is used to separate two active conducting polymer layers.

The trilayer device used in this study comprises a porous poly (vinylidene fluoride) (PVDF) substrate coated on both sides with a thin gold layer, upon which the conducting polymer, 


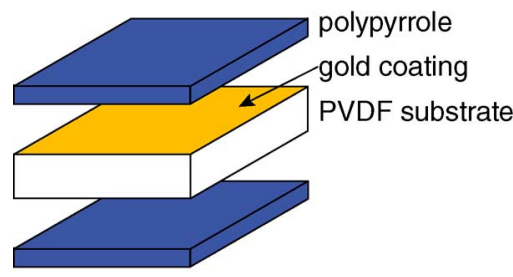

(a)
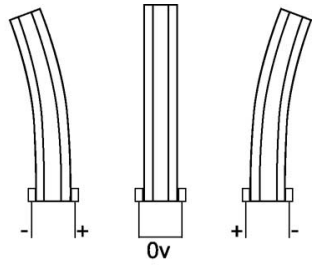

(b)
Fig. 1. (a) Exploded view of an actuator cross section. The PVDF substrate is coated on either side by gold, upon which the polypyrrole is electrochemically grown. (b) Schematic depicting the neutral position of a trilayer conducting polymer actuator (center) and its movement as a voltage is applied (left and right).

polypyrrole (PPy), is deposited [Fig. 1(a)]. The porous substrate acts as an electrical insulator between the two polymer layers while also storing electrolyte, facilitating its operation in air.

The bending action of the conducting polymer is linked to the applied voltage and the subsequent electrochemical response. In any given state, the conducting polymer structure will contain some level of charge and, to maintain electroneutrality, the free charged ions in the electrolyte will move to balance it. The application of potential across the trilayer actuator structure modifies the amount of charge in each polymer layer (lowering it on one side and increasing it on the other) and to balance this change, the free ions in the electrolyte are forced to move. The movement of these ions is associated with a change in volume [10], [19], [21]; for the actuators used in this study, as the polymer becomes more negatively charged, the negative ions will leave the polymer and it will shrink, and conversely, as the polymer becomes more positively charged (through the loss of electrons), negative ions will enter the polymer and it will expand. As each layer changes volume differently, strain differentials are produced through the actuator, causing it to bend away from the expanding layer [Fig. 1(b)]. Other mechanisms may contribute to the volume change, including solvent movement [21], [22], but these effects have not been included in the modeling discussed here, as they are slower processes and have minimal effect on the resonant frequency.

\section{MODEL}

Wu et al. [7] proposed a general model for the resonant frequency of a trilayer conducting polymer actuator, but it was not experimentally validated. This section will present a specific model for the trilayer structure, which relates the resonant frequency to actuator geometry and tip loading.

The structure of the conducting polymer actuator is presented in Fig. 2, with the width of the actuator designated as $b$, the actuator free length as $l$, and a neutral axis defined at the center of the trilayer structure. The thicknesses of the laminated layers of the actuator are described by the height of the PVDF $h_{1}$ and the polypyrrole $h_{2}$ from the neutral axis. The elastic modulus of the polypyrrole is $E_{\mathrm{ppy}}$ and $E_{\mathrm{pvdf}}$ for the PVDF substrate. The density of the polypyrrole is $\rho_{\text {ppy }}$ and $\rho_{\text {pvdf }}$ for the PVDF. The gold coating on the PVDF has been assumed to have negligible effect on the mechanical operation of the actuator.

Considering the dimensions of the actuator and the material densities, the mass of the actuator can be described as

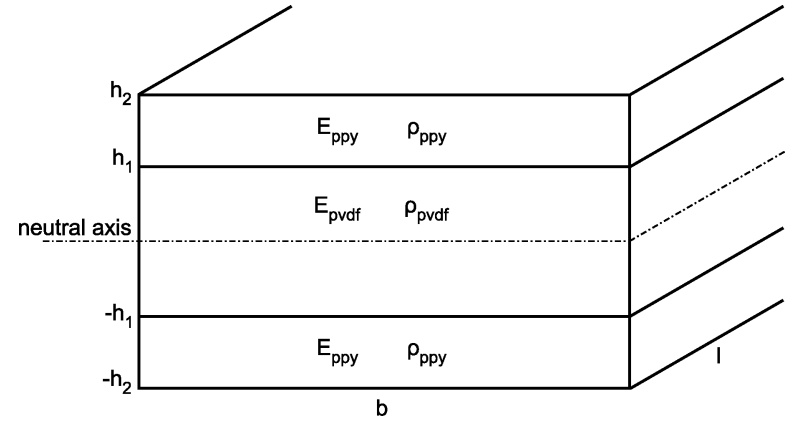

Fig. 2. Labeled schematic of a trilayer actuator cross section.

follows:

$$
m=2 l b h_{1} \rho_{\text {pvdf }}+2 l b\left(h_{2}-h_{1}\right) \rho_{\text {ppy }} .
$$

It is assumed that, given one end of the trilayer is fixed and the other free to move, the actuator can be modeled as a cantilever. The resonant frequency, in Hertz, and subsequent harmonics for a cantilever beam of length $l$ and mass $m$ can be shown to be [23]

$$
f_{n, \text { beam }}^{2}=\frac{1}{4 \pi^{2}} \frac{\beta^{4}}{l^{3}}\left(\frac{E I}{m}\right)
$$

where $\beta$ is the resonant frequency mode ( 1.875 for fundamental resonance) and $E I$ is the flexural rigidity of the beam; however, this derivation does not consider any effect of tip loading. The resonant frequency for a mass $m_{t}$ at the tip of a zero-mass beam of length $l$ is given by [24]

$$
f_{n, \mathrm{mass}}^{2}=\frac{1}{4 \pi^{2}} \frac{3 E I}{m_{t} l^{3}} .
$$

Assuming that the lengths of the beam for the cantilever with and without tip mass are identical, Dunkerley's formula (4) [24] can be used to find the combined resonant frequencies (5). It must be noted that Dunkerley's formula is an empirical relationship, and has been used here for simplicity. It does not represent a closed-form solution for trilayer resonance while loaded

$$
\begin{aligned}
f_{n}^{2} & =\frac{f_{n, \text { beam }}^{2} \times f_{n, \text { mass }}^{2}}{f_{n, \text { beam }}^{2}+f_{n, \text { mass }}^{2}} \\
f_{n}^{2} & =\frac{1}{4 \pi^{2}} \frac{3 \beta^{4}}{3 m+\beta^{4} m_{t}} \frac{E I}{l^{3}} .
\end{aligned}
$$

The flexural rigidity, or resistance to bending, of the trilayer structure can be determined in terms of the dimensions and material properties, and is given in (6) [17]:

$$
E I=2 b\left(\frac{h_{1}^{3}}{3} E_{\mathrm{pvdf}}+\frac{h_{2}^{3}-h_{1}^{3}}{3} E_{\mathrm{ppy}}\right) .
$$

Substituting the actuator mass (1) and flexural rigidity (6) into the general resonant frequency equation (5), the resonant frequency of the trilayer actuator can be obtained in terms of its material properties

$$
\begin{aligned}
f_{n}^{2}= & \frac{1}{4 \pi^{2}} \frac{6 \beta^{4}}{6 l b\left(h_{1} \rho_{\text {pvdf }}+\left(h_{2}-h_{1}\right) \rho_{\text {ppy }}\right)+\beta^{4} m_{t}} \\
& \times \frac{b\left(\left(h_{1}^{3} / 3\right) E_{\text {pvdf }}+\left[\left(h_{2}^{3}-h_{1}^{3}\right) / 3\right] E_{\text {ppy }}\right)}{l^{3}} .
\end{aligned}
$$


When no loading has been added to the tip of the actuator, $m_{t}$ equals zero and the resonant frequency equation reduces to

$$
f_{n}^{2}=\frac{1}{4 \pi^{2}} \frac{\beta^{4}\left(\left(h_{1}^{3} / 3\right) E_{\mathrm{pvdf}}+\left[\left(h_{2}^{3}-h_{1}^{3}\right) / 3\right] E_{\mathrm{ppy}}\right)}{l^{4}\left(h_{1} \rho_{\mathrm{pvdf}}+\left(h_{2}-h_{1}\right) \rho_{\mathrm{ppy}}\right)} .
$$

The resonant frequency model with zero tip loading (8) predicts that the resonant frequency is inversely proportional to the square of length. This is equivalent to

$$
f_{n}=A l^{-2}
$$

where $A$ is given by

$$
A=\sqrt{\frac{1}{4 \pi^{2}} \frac{\beta^{4}\left(\left(h_{1}^{3} / 3\right) E_{\mathrm{pvdf}}+\left[\left(h_{2}^{3}-h_{1}^{3}\right) / 3\right] E_{\mathrm{ppy}}\right)}{\left(h_{1} \rho_{\mathrm{pvdf}}+\left(h_{2}-h_{1}\right) \rho_{\mathrm{ppy}}\right)}} .
$$

One implication of (6) is that the stress and strain distribution along the thickness of the actuator can be estimated using the flexural rigidity expressed by (6). However, it must be noted that while the stress distribution is uniform through the thickness of our actuators for thicknesses up to $50 \mu \mathrm{m}$ [16], the strain distribution is linearly increasing from the neutral axis of the actuator to the surface of the actuator along the thickness.

\section{EXPERIMENTAL CONFIGURATION}

\section{A. Trilayer Actuators}

Conducting polymer actuators, based on polypyrrole, were manufactured electrochemically using a constant current process. A full description of this process is presented in [7]. The inert substrate PVDF was first coated with a thin layer of gold using a sputter coating process. It was then cut to size and placed in a glass cell containing the monomer (pyrrole, supplier Merck), salt [lithium trifluoromethanesulfonimide $\left(\mathrm{Li}^{+} \mathrm{TFSI}^{-}\right)$, supplier $\left.3 \mathrm{M}\right], 1 \mathrm{wt} . \%$ water and solvent [Propylene Carbonate (PC), supplier Sigma-Aldrich]. A current density of $0.1 \mathrm{~mA} / \mathrm{cm}^{2}$ was applied to the PVDF using a galvanostat for either 6,12 , or $16 \mathrm{~h}$, with the thickness of the polypyrrole layer increasing by approximately $2 \mu \mathrm{m}$ per hour of growth. The polypyrrole-coated PVDF sheet is then removed from the cell, washed with acetone, and stored in $0.1 \mathrm{M} \mathrm{Li}^{+} \mathrm{TFSI}^{-}$in PC. The benders are then cut to size from the bulk sheet as required.

An example micrograph of the dry trilayer structure is shown in Fig. 3, with the PVDF membrane visible in the center, separating the two polypyrrole layers. The PVDF has a thickness of $110 \mu \mathrm{m}$ before polymerization, with an elastic modulus of approximately $307 \mathrm{MPa}$ that increases to $312 \mathrm{MPa}$ after gold coating, as estimated from the oscillation frequency of a dry cantilevered sample. The elastic modulus of the PPy grown in this configuration is unknown, but previous publications have reported moduli of $80 \mathrm{MPa}$ [11] for single films of similar manufacture.

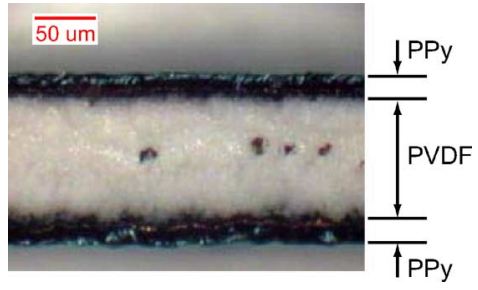

Fig. 3. Example cross-sectional micrograph of dry, $12 \mathrm{~h}$ grown actuator.

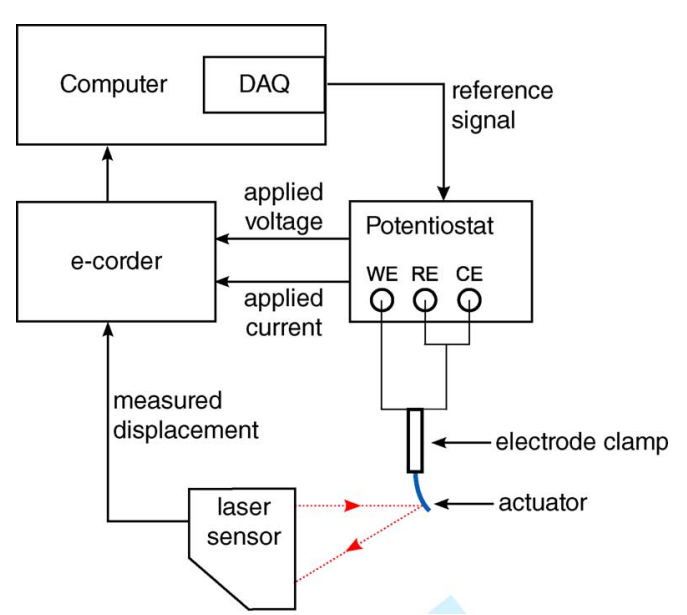

Fig. 4. Schematic of the experimental configuration. The laser displacement sensor is mounted on an XY micrometer stage. WE: working electrode; RE: reference electrode; CE: counter electrode.

\section{B. Displacement Measurement}

An experimental system was developed to measure the actuator displacement, as shown in Figs. 4 and 5. A National Instruments Data Acquisition Card (model NI6229) was used to generate a voltage signal, which was amplified by a potentiostat (eDAQ model EA161) operating in two-electrode mode. The actuator was sandwiched between two platinum contacts to apply the amplified voltage across the trilayer structure. A laser displacement sensor (microepsilon, model NCDT-170010) with $10 \mathrm{~mm}$ measurement range, $0.5 \mu \mathrm{m}$ resolution, and $2.5 \mathrm{kHz}$ bandwidth was mounted on an $X Y$ micrometer stage and used to measure the tip displacement, outputting a proportional voltage measured by an e-corder data logger (eDAQ e-corder, model ED821). The laser displacement sensor introduces a delay of approximately $2 \mathrm{~ms}$ between the displacement measurement and voltage output due to the conversion electronics, imposing a phase shift of approximately $-0.72^{\circ} / \mathrm{Hz}$ on the actuator response.

To experimentally identify the effects of tip loading on the resonant frequency response of the trilayer bender, disc magnets with a diameter of $1 \mathrm{~mm}$, thickness of $0.5 \mathrm{~mm}$, and mass of $2.79 \mathrm{mg}$ were attached to the trilayer bender in multiples of 2 . To simulate a point mass, the magnets were located at the tip of the actuator and centered with respect to its width (Fig. 7).

For all frequency-response tests, a variable-frequency (or swept) sine wave was generated using LabVIEW, with parameters as given in Table I (unless otherwise noted) and inputted into 


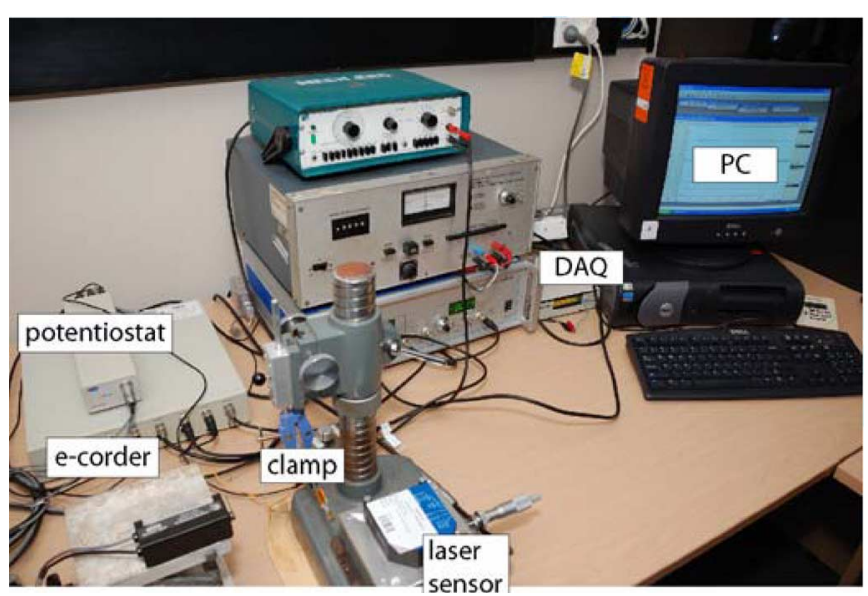

Fig. 5. Labeled photograph of experimental setup.

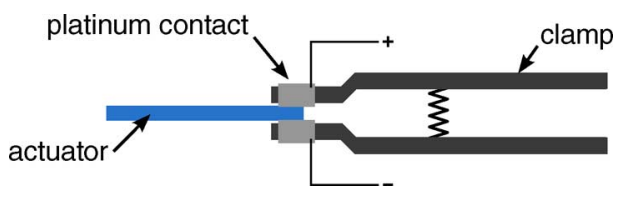

Fig. 6. Schematic of electrode clamp.

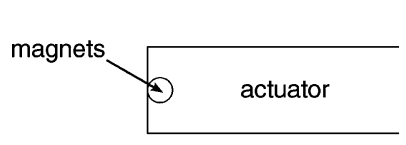

(a) (b)

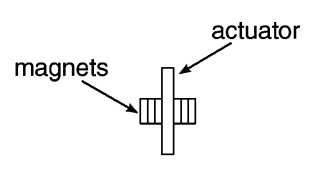

Fig. 7. Schematic of (a) side view and (b) end view of the magnets attached to the actuator, as used to simulate bender point mass loading.

TABLE I

STANDARD OUTPUT Signal PARAMETERS

\begin{tabular}{cc}
\hline \hline Parameter & Value \\
\hline Signal type & Swept sine \\
Voltage (peak) & $0.25 \mathrm{~V}$ \\
Starting frequency & $0 \mathrm{~Hz}$ \\
Frequency rate of change & $3.33 \mathrm{~Hz} /$ second \\
\hline \hline
\end{tabular}

the potentiostat as the reference voltage signal. The laser was then focussed at the tip of the actuator to measure displacement. Upon completion of the experiment, the frequency response was estimated from the time-domain data using Welch's method [25] and the damped fundamental resonant frequency measured. The damped natural frequency has been assumed to be equal to the natural frequency of the system, as the estimated damping ratio of the actuator is low (approximately 0.03 ), so the error introduced is less than $0.1 \%$ for a second-order system.

\section{EXPERIMENTAL RESULTS}

\section{A. Input Voltage}

To identify the effect of the frequency response on input voltage, a 15.75-mm-long $\times 2$-mm-wide actuator $(12 \mathrm{~h}$ growth) was clamped and the laser focused $1.0 \mathrm{~mm}$ from the tip. A swept sine wave with a frequency range of $0-50 \mathrm{~Hz}$ was then
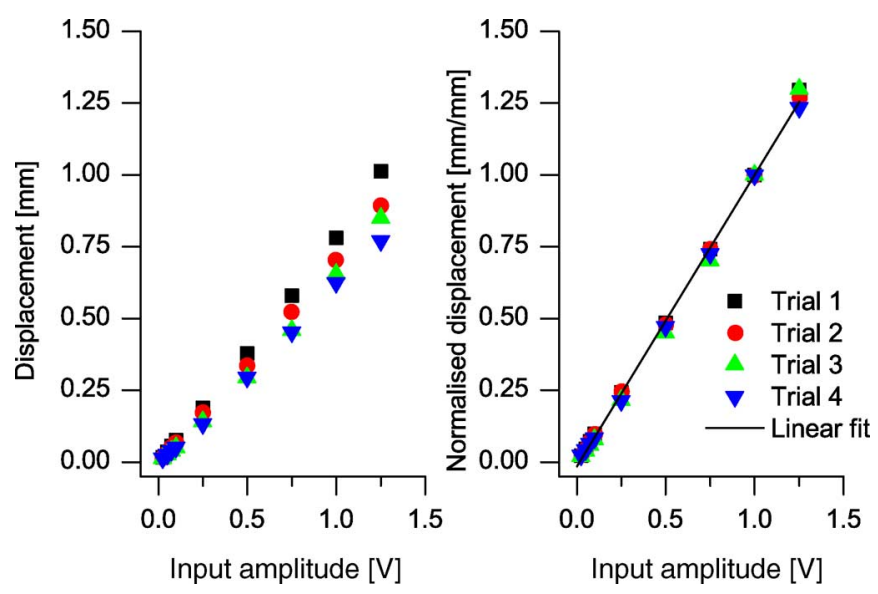

Fig. 8. Variation in fundamental resonant frequency of the test actuator as the sine wave amplitude is modified, in millimeter (left), and normalized to the $1 \mathrm{~V}$ measurement (right). A linear fit has been applied to the normalized displacement $(y=1.02 x-0.015)$. Common actuator parameters: $15.75 \mathrm{~mm}$ length, $2 \mathrm{~mm}$ width, and $12 \mathrm{~h}$ growth.
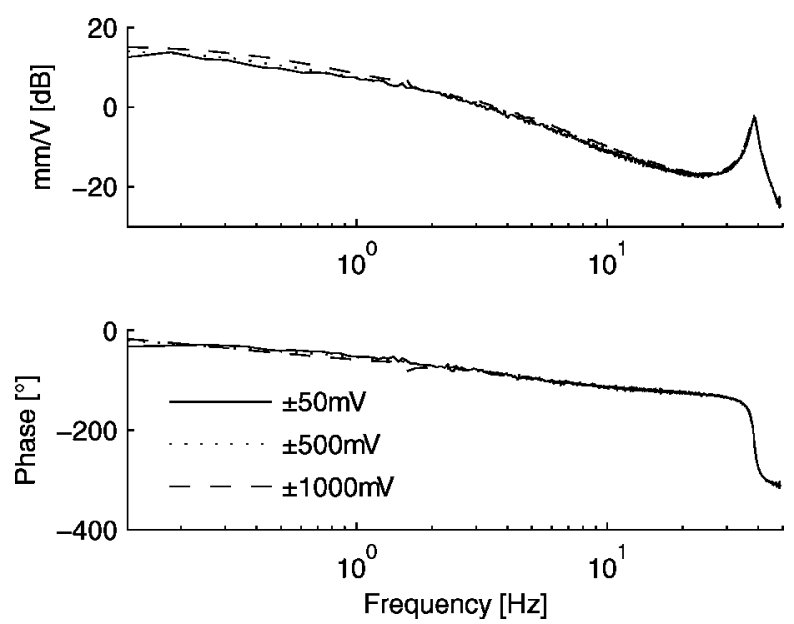

Fig. 9. Frequency response of a trilayer bender for three different input voltages. Common actuator parameters: $15.75 \mathrm{~mm}$ length, $2 \mathrm{~mm}$ width, and $12 \mathrm{~h}$ growth.

applied, with the amplitude of the signal varied in nine intervals between 0.025 and $1.250 \mathrm{~V}$. The test was repeated four times on the same actuator sample, with the actuator resoaked with electrolyte between each test. The frequency response and fundamental resonant frequencies were then identified for each input amplitude.

The average fundamental resonant frequency for all tests was $38.4 \mathrm{~Hz}$, with a standard deviation of $0.16 \mathrm{~Hz}$. The displacement at resonance for each of the four trials is given in Fig. 8 (left) and normalized against the $1 \mathrm{~V}$ measurement in Fig. 8 (right) with a linear trend line fitted. Sample frequency responses are given in Fig. 9 for three different input voltages showing both gain and phase shift, and the fundamental resonance can be seen clearly at approximately $38 \mathrm{~Hz}$. 


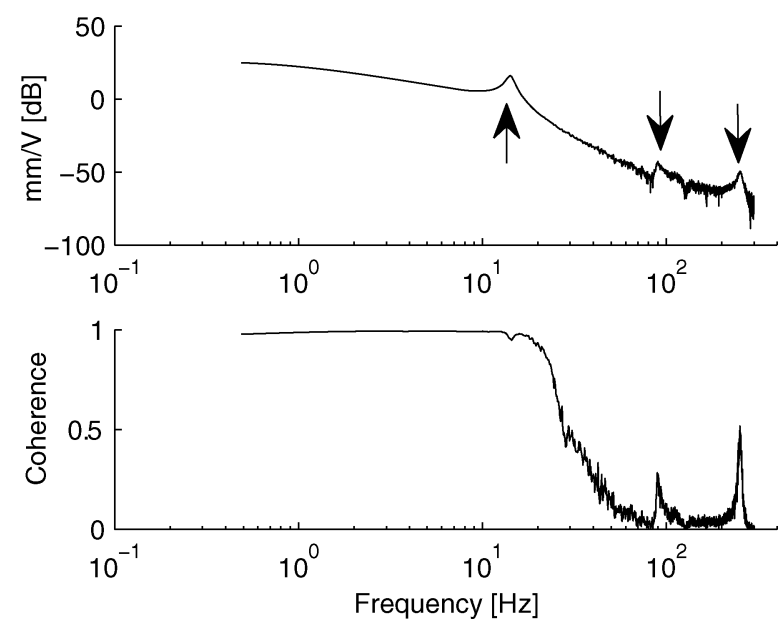

Fig. 10. Amplitude and coherence of a 25-mm-long, 2-mm-wide bender from a $12 \mathrm{~h}$ growth. The resonant peaks are indicated by the arrows.

TABLE II

HIGHER ORDER RESONANT FREQUENCIES

\begin{tabular}{cccc}
\hline \hline Mode & $\begin{array}{c}\text { Measured } \\
{[\mathrm{Hz}]}\end{array}$ & $\begin{array}{c}\text { Expected } \\
{[\mathrm{Hz}]}\end{array}$ & $\begin{array}{c}\text { Percentage } \\
\text { difference }\end{array}$ \\
\hline Fundamental & 14.2 & - & - \\
$2^{\text {nd }}$ & 89.5 & 88.7 & $0.8 \%$ \\
$3^{\text {rd }}$ & 252.1 & 248.5 & $1.4 \%$ \\
\hline \hline
\end{tabular}

\section{B. Higher Resonance Modes}

A frequency response was obtained for a 25-mm-long, 2-mmwide trilayer bender from a $12 \mathrm{~h}$ growth up to $300 \mathrm{~Hz}$ (Fig. 10). The laser was focussed at $20 \mathrm{~mm}$ from the clamp, allowing the first three resonance modes to be identified, as shown in Table II. The expected frequencies are also presented, based on the measured fundamental resonance of $14.2 \mathrm{~Hz}$ and vibrations modes of $\beta=4.694$ (second mode) and $\beta=7.855$ (third mode).

\section{Geometry Variation}

The geometry of the conducting polymer was varied and the fundamental resonant frequency measured. The factors under consideration were actuator length, width, polymer thickness, and loading of the actuator (or tip mass).

The changes in resonant frequency as a function of length are presented in Fig. 11(a)-(f) inclusive. The function $f_{n}=A l^{-2}$ [see (10)] has been fitted to each of the resonant frequency measurements using least-squares regression and is presented in each subplot of Fig. 11 as the solid line. Fig. 12 presents sample displacement frequency responses for three different length actuators.

Each row in Fig. 11 [(a) and (b), for example] presents the resonant frequency results for variation in actuator width for a number of actuator lengths. Sample frequency response plots are presented in Fig. 13 for a 2- and 4-mm-wide actuator.

The change in the fundamental resonant frequency with PPy thickness is presented in each column of Fig. 11 [(a), (c), and (e), for example] for a number of different actuator lengths. Fig. 15 presents sample frequency response plots for three actuators of identical length and width but different PPy thickness.

Polymer actuators were cut to size from the $12 \mathrm{~h}$ growth to widths of $2-4 \mathrm{~mm}$ and free lengths of $5.75,10.75$, and $15.75 \mathrm{~mm}$. The tip of the actuator was progressively loaded from 0 to $40 \mathrm{mg}$ and the fundamental resonant frequency measured.

The results for the mass variation experiments are presented in Fig. 14(a)-(f), with each row for a specific length and each column for a specific width and the solid line representing the fitted model. Sample frequency responses are presented in Fig. 16 for a fixed actuator length and width as the tip mass is varied.

\section{DISCUSSION}

\section{A. Voltage Independence}

The fundamental resonant frequency has been found to be independent of input voltage (Fig. 9). The elastic modulus of a polypyrrole film has been reported to change with applied potential [11] over longer time periods; however, the fundamental resonant frequency does not change with input voltage amplitude, which indicates that there is minimal change in the bulk elastic modulus when interpreted using the resonant frequency model (7).

\section{B. Resonant Frequency and Geometry Variation}

The fundamental resonant frequency of the trilayer actuator was found to be a function of length, increasing as the length of the actuator was decreased for all actuator widths and polymer thicknesses tested [Fig. 11(a)-(f) inclusive]. There is also good repeatability between individual experiments, as can be seen by the small variation between the three actuators tested at each measurement. The fitted resonant frequency model followed the experimental measurements closely (Fig. 11, solid line), indicating that the model is valid for the range of dimensions tested.

The magnitude of the amplitude response of the actuator decreases as the length of the actuator decreases (Fig. 12). This result is expected, given that the shorter actuators produce less bending at the tip of the actuator for a given input.

An increase in actuator width from 2 to $4 \mathrm{~mm}$ does not produce a significant change in the fundamental resonant frequency for each thickness and length, as shown in each row of Fig. 11 [such as (a) and (b)]. This can be verified by comparing the coefficient $A$ fitted to the resonant frequency measurements (Table III), confirming the resonant frequency model for zero tip loading (8), because any rise in the actuator mass is balanced by an increase in flexural rigidity.

It was found that the fundamental resonant frequency increased with the thickness of the PPy, as shown in each column of Fig. 11 [such as (a), (c), and (e)], following the trends predicted by the resonant frequency model (8).

As load is applied to the tip of the trilayer bender, the fundamental resonant frequency becomes dependent on width, following the prediction of the full resonant frequency model (7). Further validation was obtained by fitting a reduced-complexity resonant frequency model (5) to the experimental observations, 

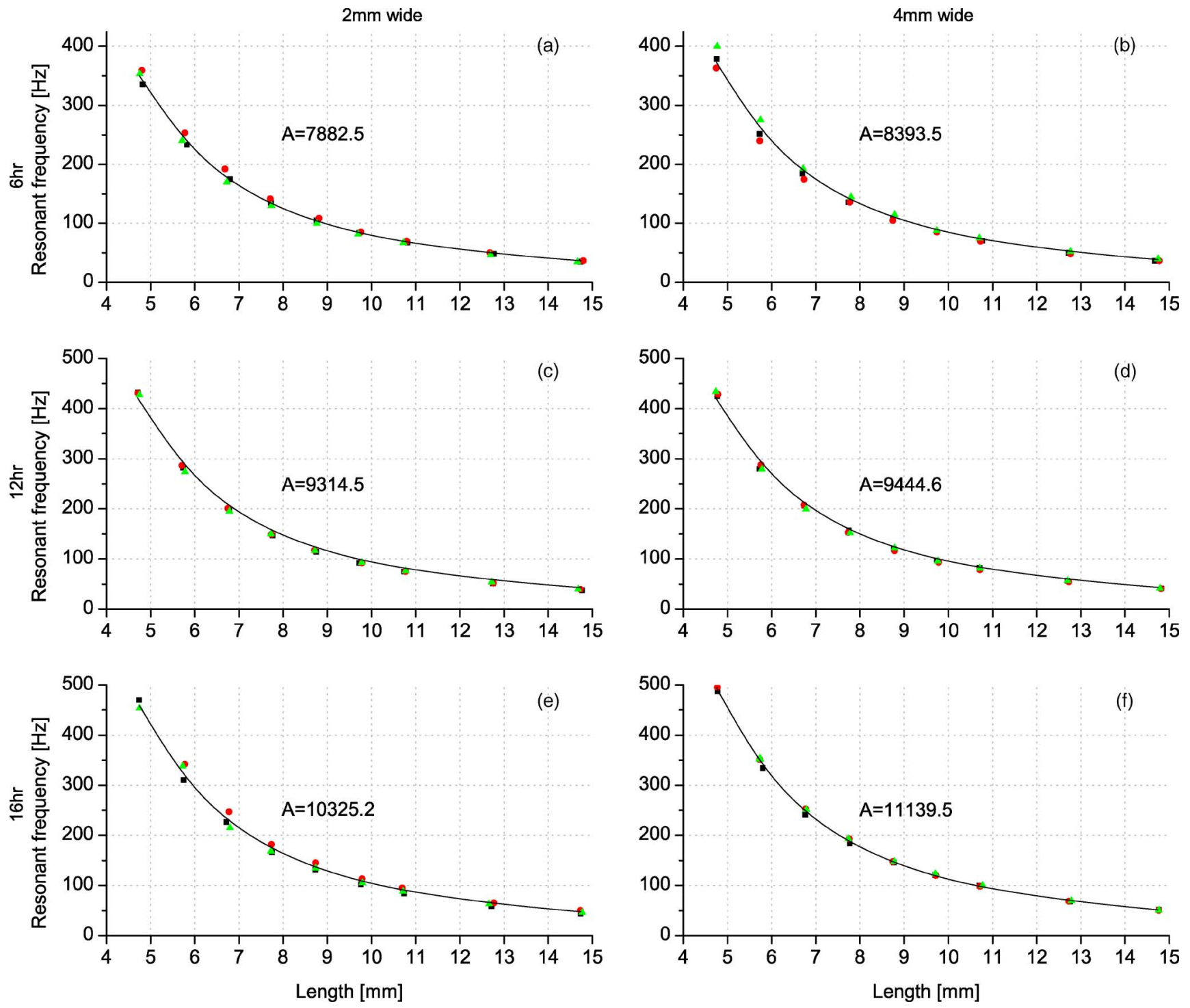

Fig. 11. Experimental resonant frequency results for various actuator geometries. Each subplot [(a)-(f)] is the fundamental resonant frequency versus actuator length, each column is for a specific actuator width, while each row is for a specific polypyrrole thickness. Three trials were performed for each actuator dimension,

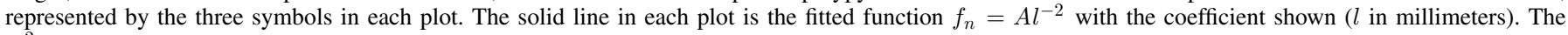
$R^{2}$-value for all fits was greater than 0.99 .
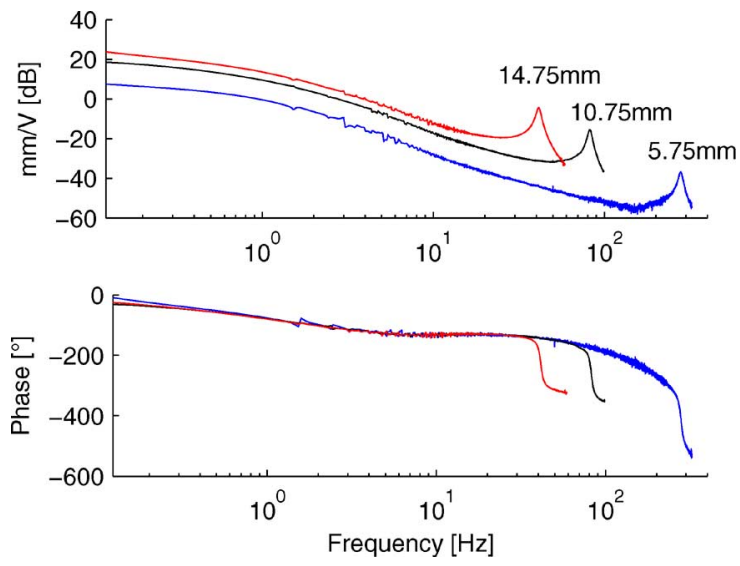

Fig. 12. Frequency responses of a 14.75-, 10.75-, and 5.75-mm-long actuator. Common actuator parameters: $4 \mathrm{~mm}$ width, $12 \mathrm{~h}$ growth.
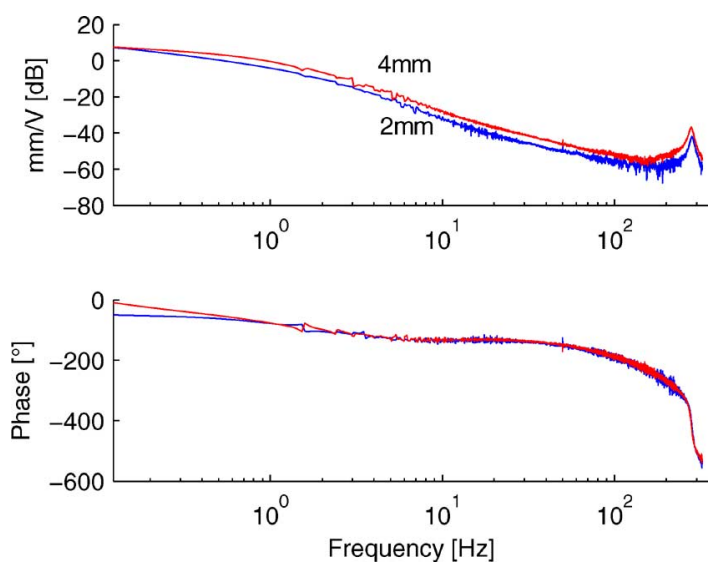

Fig. 13. Frequency response of a 2-mm-wide (lower) and 4-mm-wide (upper) actuator. Common actuator parameters: $5.75 \mathrm{~mm}$ length, $12 \mathrm{~h}$ growth. 

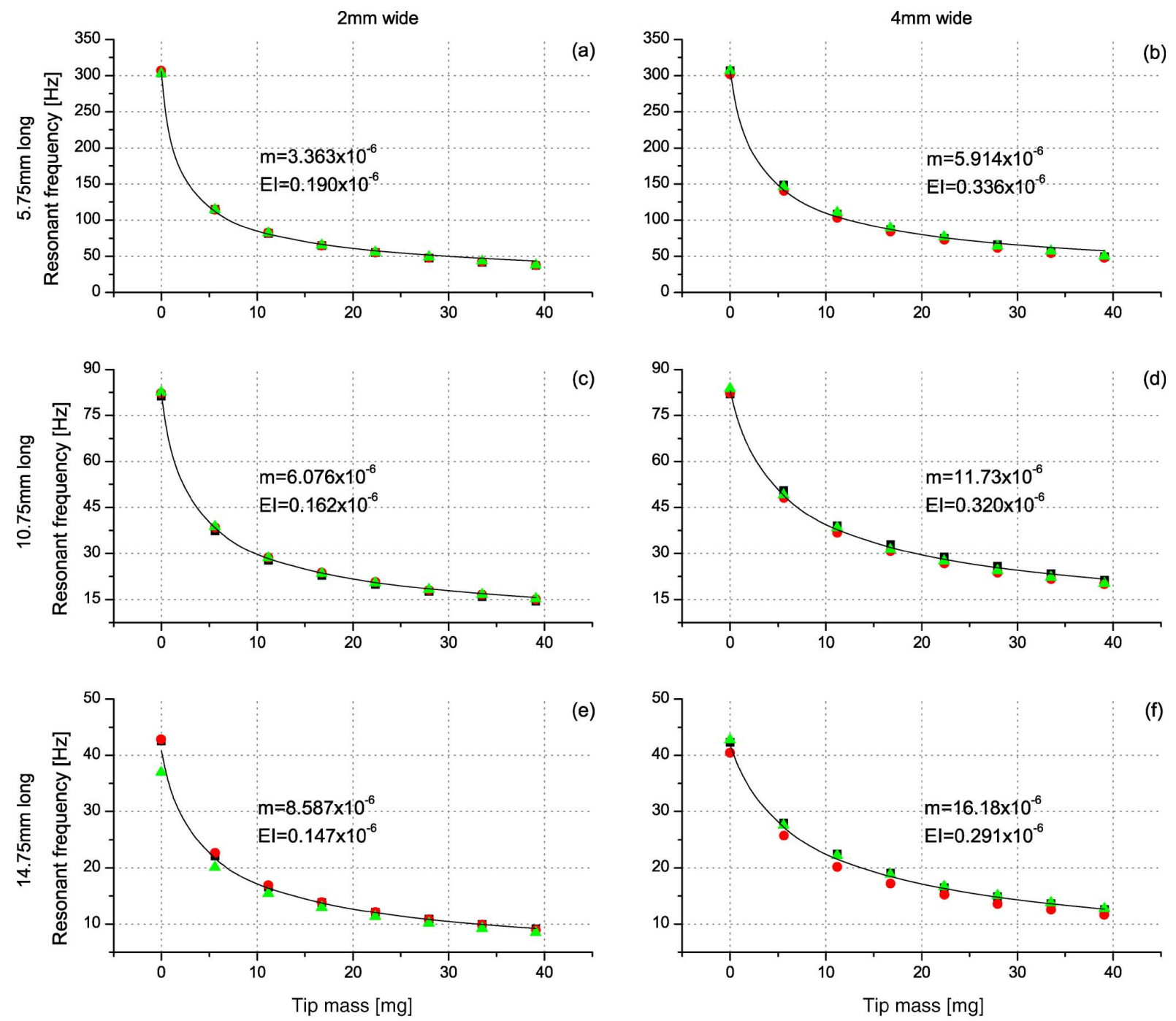

Fig. 14. Fundamental resonant frequency measurements versus actuator tip mass for $12 \mathrm{~h}$ growth actuators with widths of 2 or $4 \mathrm{~mm}$ (columns) and lengths of $14.75,10.75$, and $5.75 \mathrm{~mm}$ (rows). Three tests were performed for each actuator dimension, represented by the three symbols. The resonant frequency model has been fitted to each dimension (solid lines), with fitted coefficients $m$ (kilogram) and $E I$ (Newton square meter) given. The $R^{2}$-value for each fit was greater than 0.99 .
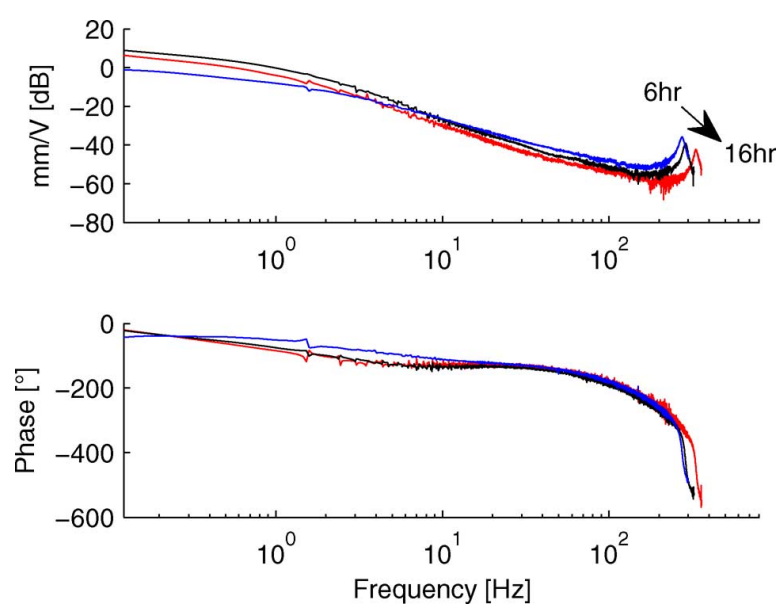

Fig. 15. Frequency response for three actuators of differing thicknesses, $6 \mathrm{~h}$ (left peak), 12 and $16 \mathrm{~h}$ (right peak) growths. Common actuator parameters: $5.75 \mathrm{~mm}$ length, $4 \mathrm{~mm}$ width.
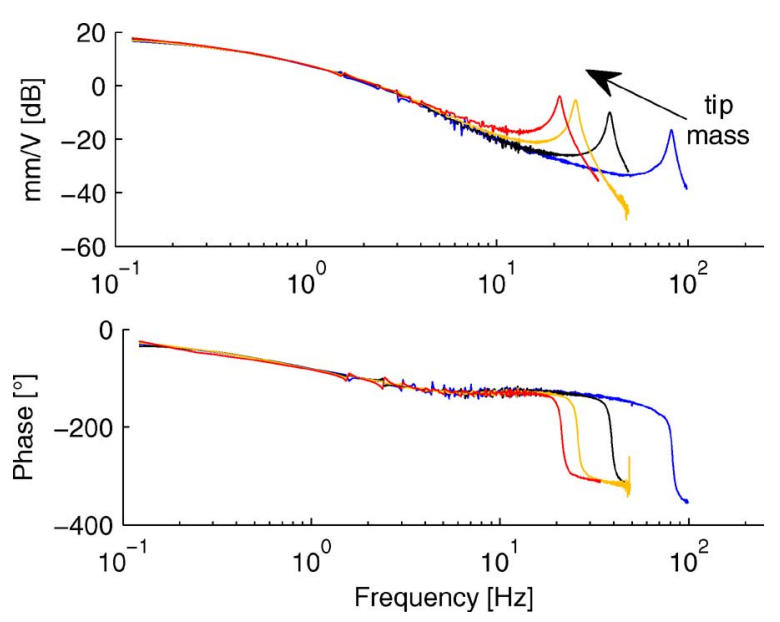

Fig. 16. Frequency response of an actuator with $0,11.2,27.9$, and $39.1 \mathrm{mg}$ tip loadings. The arrow indicates tip mass increasing from low $(0 \mathrm{mg}$, right) to high $(39.1 \mathrm{mg}$, left). Common actuator parameters: $10.7 \mathrm{~mm}$ length, $4 \mathrm{~mm}$ width, and $12 \mathrm{~h}$ growth. 
TABLE III

COMPARISON OF FITTED LENGTH COEFFICIENTS $A$

\begin{tabular}{cccc}
\hline \hline $\begin{array}{c}\text { PPy Growth } \\
\text { Duration }\end{array}$ & $\begin{array}{c}2 \mathrm{~mm} A \\
\text { coefficient }\end{array}$ & $\begin{array}{c}4 \mathrm{~mm} A \\
\text { coefficient }\end{array}$ & $\begin{array}{c}\text { Percentage } \\
\text { difference }\end{array}$ \\
\hline $6 \mathrm{hr}$ & 7882.5 & 8393.5 & $6.1 \%$ \\
$12 \mathrm{hr}$ & 9314.5 & 9444.6 & $1.4 \%$ \\
$16 \mathrm{hr}$ & 10325.2 & 11139.5 & $7.3 \%$ \\
\hline \hline
\end{tabular}

TABLE IV

COMPARISON OF EXPECTED AND FITTED ACTUATOR MASSES

\begin{tabular}{cccc}
\hline $\begin{array}{c}\text { Actuator } \\
\text { dimension }[\mathrm{mm}]\end{array}$ & $\begin{array}{c}\text { Estimated mass } \\
{[\mathrm{mg}]}\end{array}$ & $\begin{array}{c}\text { Expected mass } \\
{[\mathrm{mg}]}\end{array}$ & $\begin{array}{c}\text { Percentage } \\
\text { difference [\%] }\end{array}$ \\
\hline 5.75 by 4 & 5.9 & 6.0 & $-1.7 \%$ \\
10.75 by 4 & 11.7 & 11.2 & $4.3 \%$ \\
14.75 by 4 & 16.2 & 15.3 & $5.6 \%$ \\
\hline \hline
\end{tabular}

TABLE V

COMPARISON OF THEORETICAL AND EXPERIMENTAL FLEXURAL RIGIDITY

\begin{tabular}{ccccc}
\hline \hline $\begin{array}{c}\text { Actuator } \\
\text { length }\end{array}$ & $\begin{array}{c}2 \mathrm{~mm} \mathrm{EI} \\
{\left[N \cdot m^{2}\right]}\end{array}$ & $\begin{array}{c}4 \mathrm{~mm} \text { EI } \\
{\left[N \cdot m^{2}\right]}\end{array}$ & $\begin{array}{c}\text { Experimental } \\
2 \mathrm{~mm} \mathrm{EI} / 4 \mathrm{~mm} \text { EI }\end{array}$ & $\begin{array}{c}\text { Theoretical } \\
2 \mathrm{~mm} \text { EI/4mm EI }\end{array}$ \\
\hline $5.75 \mathrm{~mm}$ & $1.90 \mathrm{E}-07$ & $3.36 \mathrm{E}-07$ & 0.57 & 0.50 \\
$10.75 \mathrm{~mm}$ & $1.62 \mathrm{E}-07$ & $3.20 \mathrm{E}-07$ & 0.51 & 0.50 \\
$14.75 \mathrm{~mm}$ & $1.47 \mathrm{E}-07$ & $2.90 \mathrm{E}-07$ & 0.51 & 0.50 \\
\hline \hline
\end{tabular}

as shown in Fig. 14. The fitted mass (Table IV) and fitted flexural rigidity (Table V) coefficients are within experimental error.

\section{Applications of the Model}

The model can be used to estimate the position of the resonant frequency as part of a full frequency response model, when all material properties are known. As displacement can be difficult to control around resonance given the sharp changes in amplitude, the model could be used to predict the center frequency, allowing the resonance to be avoided.

Monitoring of the resonant frequency during operation would allow any changes in the loading of the actuator to be detected.

If the resonant frequency is known and some actuator properties are not, then the model could be used to estimate these unknowns. For example, this technique was applied to the model fitted to the variable tip mass results (Fig. 14) to closely estimate the mass of the actuator. If the dimensions and masses of the individual actuator layers and the elastic modulus of the PVDF substrate were known, then the elastic modulus of the polypyrrole could be estimated from the flexural rigidity by using (6).

\section{CONCLUSION}

Trilayer conducting polymer actuators show promise for practical devices, as they produce useable forces and displacements from small input voltages, but the dynamic behavior of the actuators has not previously been fully identified or understood. In an effort to identify these dynamics of the actuator, the frequency response of the actuator displacement has been identified for both gain and phase using a laser displacement sensor. The technique has been shown to be independent of input voltage and actuator displacement.
The four controllable parameters of the resonant frequency equation-length, width, polymer thickness, and tip masshave all been varied independently, and the trends shown by these actuators match those predicted by the model for resonant frequency. Furthermore, the higher resonant modes matched model predictions, while the fitted model parameters were all within the ranges expected for the system, indicating that the model is valid for this particular actuator configuration. Future work will use the resonant frequency model and experimentally identified frequencies to estimate the elastic modulus of the conducting polymer.

This paper has identified the frequency response of the trilayer actuator and has modeled one characteristic, the resonant frequency, representing a step toward the understanding and modeling of the entire frequency response. Future work will identify the transfer function of the system, then link it to the resonant frequency model and the mechanisms behind actuation; identifying and understanding these factors will allow optimization of the open loop displacement and the design of compensating controllers to ultimately allow their use in functional devices.

\section{ACKNOWLEDGMENT}

The authors would like to thank the members of the Intelligent Polymer Research Institute at the University of Wollongong for the kind assistance in the preparation of trilayer actuators.

\section{REFERENCES}

[1] R. H. Baughman, "Conducting polymer artificial muscles," Synthetic Metals, vol. 78, pp. 339-353, 1996.

[2] E. Smela, "Microfabrication of PPy microactuators and other conjugated polymer devices," J. Micromech. Microeng., vol. 9, pp. 1-18, 1999.

[3] G. Alici and N. N. Huynh, "Performance quantification of conducting polymer actuators for real applications: A microgripping system," IEEE/ASME Trans. Mechatronics, vol. 12, no. 1, pp. 73-84, Feb. 2007.

[4] E. H. Jager, O. Inganas, and I. Lundstrom, "Microrobots for micrometersize objects in aqueous media: Potential tools for single-cell manipulation," Science, vol. 288, pp. 2335-2338, 2000.

[5] J. W. L. Zhou, H.-Y. Chan, T. K. H. To, K. W. C. Lai, and W. J. Li, "Polymer MEMS actuators for underwater micromanipulation," IEEE/ASME Trans. Mechatronics, vol. 9, no. 2, pp. 334-342, Jun. 2004.

[6] G. Alici and N. N. Huynh, "Predicting force output of trilayer polymer actuators," Sens. Actuators A, vol. 132, pp. 616-625, 2006.

[7] Y. Wu, G. Alici, G. M. Spinks, and G. G. Wallace, "Fast trilayer polypyrrole bending actuators for high speed applications," Synthetic Metals, vol. 156, pp. 1017-1022, 2006.

[8] S. Hara, T. Zama, W. Takashima, and K. Kaneto, "Free-standing gellike polypyrrole actuators doped with bis(perfluoroalkylsulfonyl)imide exhibiting extremely large strain," Smart Mater. Struct., vol. 14, pp. 1501$1510,2005$.

[9] J. D. Madden, R. A. Cush, T. S. Kanigan, and I. W. Hunter, "Fast contracting polypyrrole actuators," Synthetic Metals, vol. 113, pp. 185-192, 2000.

[10] J. D. W. Madden, P. G. A. Madden, and I. W. Hunter, "Polypyrrole actuators: Modeling and performance," in Proc. Smart Struct. Mater. 2001: Electroactive Polymer Actuators Devices, pp. 72-83.

[11] G. M. Spinks, L. Lu, G. G. Wallace, and D. Zhou, "Strain response from polypyrrole actuators under load," Adv. Functional Mater, vol. 12, pp. $437-440,2002$.

[12] G. M. Spinks, B. Xi, D. Zhou, V.-T. Truong, and G. G. Wallace, "Enhanced control and stability of polypyrrole electromechanical actuators," Synthetic Metals, vol. 140, pp. 273-280, 2004.

[13] J. D. Madden, "Conducting polymer actuators," Ph.D. dissertation, Dept. Mech. Eng., Massachusetts Inst. Technol., Cambridge, 2000.

[14] A. Della Santa, D. De Rossi, and A. Mazzoldi, "Characterization and modelling of a conducting polymer muscle-like linear actautor," Smart Mater. Struct., vol. 6, pp. 23-34, 1997. 
[15] J. Ding, L. Liu, G. M. Spinks, D. Zhou, G. G. Wallace, and J. Gillespie, "High performance conducting polymer actuators utilising a tubular geometry and helical wire interconnects," Synthetic Metals, vol. 138, pp. 391-398, 2003.

[16] G. Alici, P. Metz, and G. M. Spinks, "A methodology towards geometry optimization of high performance polypyrrole (PPy) actuators," Smart Mater. Struct., vol. 15, pp. 243-252, 2006.

[17] G. Alici, B. Mui, and C. Cook, "Bending modeling and its experimental verification for conducting polymer actuators dedicated to manipulation applications," Sens. Actuators A, vol. 126, pp. 396-404, 2006.

[18] K. Kaneto, M. Kaneko, Y. Min, and A. G. MacDiarmid, "Artificial muscle: Electromechanical actuators using polyaniline films," Synthetic Metals, vol. 71, pp. 2211-2212, 1995.

[19] Q. Pei and O. Inganas, "Electrochemical applications of the bending beam method. 1. Mass transport and volume changes in polypyrrole during redox," J. Phys. Chem., vol. 96, pp. 10507-10514, 1992.

[20] Q. Pei and O. Inganas, "Electrochemical applications of the bending beam method. 2. Electroshrinking and slow relaxation in polypyrrole," J. Phys. Chem., vol. 97, pp. 6034-6041, 1993.

[21] R. H. Baughman, L. W. Shacklette, R. L. Elsenbaumer, E. J. Plichta, and C. Becht, "Micro electromechanical actuators based on conducting polymers," in Molecular Electronics, P. I. Lazarev, Ed. Dordrecht, The Netherlands: Kluwer, 1991, pp. 267-289.

[22] L. Bay, T. Jacobsen, and S. Skaarup, "Mechanism of actuation in conducting polymers: Osmotic expansion," J. Phys. Chem. B, vol. 105, pp. 8492$8497,2001$.

[23] A. D. Dimarogonas and S. Daddad, Vibration for Engineers. Englewood Cliffs, NJ: Prentice-Hall, 1992.

[24] W. T. Thomson, Theory of Vibration With Applications. Englewood Cliffs, NJ: Prentice-Hall, 1989.

[25] L. Ljung, System Identification: Theory for the User. Upper Saddle River, NJ: Prentice-Hall, 1999.

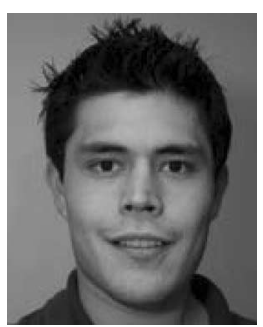

Stephen W. John received the B.E. (Hons., First Class) degree in mechatronics engineering in 2004 from the University of Wollongong, Wollongong, NSW, Australia, where he is currently working toward the Ph.D. degree in engineering.

$\mathrm{He}$ is currently with the School of Mechanical, Materials and Mechatronic Engineering, University of Wollongong.

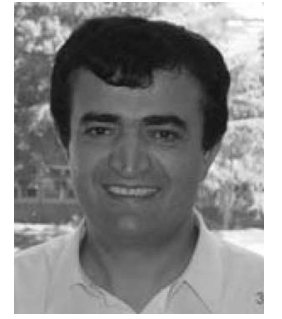

Gursel Alici received the Ph.D degree in robotics from the Department of Engineering Science, Oxford University, Oxford, U.K., in 1993.

$\mathrm{He}$ is currently an Associate Professor of mechatronic engineering at the University of Wollongong, Wollongong, NSW, Australia, where he heads the Department of Mechatronic Engineering. His current research interests include intelligent mechatronic systems involving mechanisms/serial/parallel robot manipulators, micro-/nanorobotic manipulation systems, and modeling, analysis, characterization, control, and micro-/nanofabrication of conducting polymer actuators and sensors for robotic and bioinspired applications.

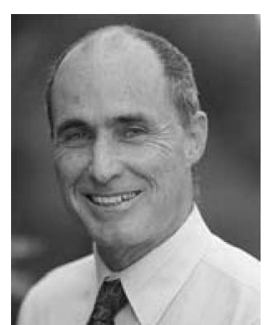

Christopher D. Cook received the B.Sc. (Physics) and B.E. (Electrical) degrees from the University of Adelaide, Adelaide, S.A., in 1971 and 1972, respectively, and the Ph.D. (Power Engineering) degree from the University of New South Wales, Kensington, NSW, Australia, in 1976.

He was with the General Electric Company (GEC) Marconi Avionics, Edinburgh, U.K., where he was engaged on the design of computers for various aerospace applications and after three years, returned to Australia to work for the Automation and Control Division, GEC, as a Technical Manager in the area of industrial automation. In 1983, he joined the University of Wollongong, Wollongong, NSW, Australia, where he became a Professor of electrical engineering in 1989 and the Dean of engineering in 2002. His current research interests include industrial automation and power engineering. 